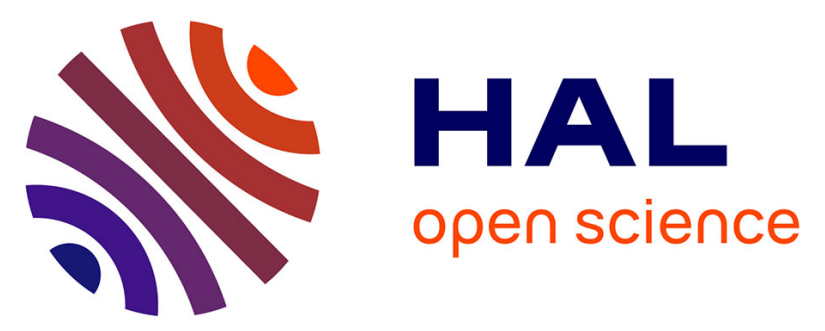

\title{
A numerical study of cavitation and bubble dynamics in liquid CO2 near the critical point
}

Hong-Son Pham, Nicolas Alpy, S. Mensah, Mark Tothill, Jean-Henry Ferrasse, Olivier Boutin, Johann Quenaut, Gilles Rodriguez, Manuel Saez

\section{- To cite this version:}

Hong-Son Pham, Nicolas Alpy, S. Mensah, Mark Tothill, Jean-Henry Ferrasse, et al.. A numerical study of cavitation and bubble dynamics in liquid $\mathrm{CO} 2$ near the critical point. International Journal of Heat and Mass Transfer, 2016, 102, pp.174-185. 10.1016/j.ijheatmasstransfer.2016.06.005 . hal01461785

\section{HAL Id: hal-01461785 \\ https://hal.science/hal-01461785}

Submitted on 21 Apr 2021

HAL is a multi-disciplinary open access archive for the deposit and dissemination of scientific research documents, whether they are published or not. The documents may come from teaching and research institutions in France or abroad, or from public or private research centers.
L'archive ouverte pluridisciplinaire HAL, est destinée au dépôt et à la diffusion de documents scientifiques de niveau recherche, publiés ou non, émanant des établissements d'enseignement et de recherche français ou étrangers, des laboratoires publics ou privés.

\section{(c)(1)}

Distributed under a Creative Commons Attribution| 4.0 International License 


\title{
A numerical study of cavitation and bubble dynamics in liquid $\mathrm{CO}_{2}$ near the critical point
}

\author{
H.S. Pham ${ }^{a}$, N. Alpy ${ }^{\mathrm{a}, *}$, S. Mensah ${ }^{\mathrm{b}}$, M. Tothill ${ }^{\mathrm{c}}$, J.H. Ferrasse ${ }^{\mathrm{d}}$, O. Boutin ${ }^{\mathrm{d}}$, J. Quenaut ${ }^{\mathrm{c}}$, G. Rodriguez $^{\mathrm{e}}$, \\ M. Saez ${ }^{\mathrm{a}}$ \\ ${ }^{a}$ CEA Cadarache, DEN/DER/SESI/LEMS, FR-13108 Saint-Paul-lez-Durance, France \\ ${ }^{\mathrm{b}}$ Aix-Marseille Université, CNRS, ECM, LMA UPR 7051, FR-13453 Marseille, France \\ ${ }^{\mathrm{C}}$ GE Power, Brown Boveri Strasse 7, CH-5401 Baden, Switzerland \\ ${ }^{\mathrm{d}}$ Aix-Marseille Université, CNRS, ECM, M2P2 UMR 7340, FR-13451 Marseille, France \\ ${ }^{\text {e }}$ CEA Cadarache, DEN/DER, FR-13108 Saint-Paul-lez-Durance, France
}

\begin{abstract}
This study aims to provide insights into the cavitation and bubble dynamics in liquid $\mathrm{CO} 2$ near the critical point. It is inspired by a previous work that reports the absence of dysfunctional behavior during the operation of a test compressor in the two-phase region of CO2. First, several characteristic parameters in the literature have suggested that thermal effects have significant impact on the dynamics of a $\mathrm{CO} 2$ bubble. These effects lead to the change of vapor pressure inside the bubble, impeding the motion of the bubble interface. As a consequence, the $\mathrm{CO} 2$ bubble collapse should feature a slow contraction of the bubble interface and the absence of noticeable pressure rise. In addition, a dynamic model has been proposed to quantitatively study the bubble collapse in liquid CO2 near the critical point. Simulation results have confirmed the qualitative prediction given by characteristic parameters. They have also revealed that the thermal layer inside the bubble has an important contribution to the bubble dynamics, in addition to the one outside the bubble, by altering the rate of phase change at the interface. These pre-dicted results appear to be in line with the aforementioned experimental observations.
\end{abstract}

\section{Introduction}

Cavitation - the formation of vapor cavities in the bulk liquid is the consequence of a rapid depressurization of the liquid to a sufficiently low pressure. When subjected to high pressure, these voids collapse, causing dysfunctional behaviors or detrimental effects to the mechanical structure such as vibrations, noises and erosion. Perceived as an undesirable phenomenon, cavitation has been the subject of interest in many engineering applications. Numerous theoretical and experimental studies have been conducted over the last century, reflecting the motivation of researchers in explaining the mechanism that leads these tiny bubbles to cause serious structural damage.

\footnotetext{
* Corresponding author.

E-mail addresses: hong-son.pham@cea.fr (H.S. Pham), nicolas.alpy@cea.fr (N. Alpy), mensah@lma.cnrs-mrs.fr (S. Mensah), mark.tothill@ge.com (M. Tothill), jean-henry.ferrasse@univ-amu.fr (J.H. Ferrasse), olivier.boutin@univ-amu.fr (O. Boutin), johann.quenaut@ge.com (J. Quenaut), gilles.rodriguez@cea.fr (G. Rodriguez), manuel.saez@cea.fr (M. Saez).
}

Rayleigh [23], in attempting to reveal the mysterious metal erosion on ship propellers, proposed a pressure dynamic theory for the collapse of spherical bubbles. He predicted that shock waves released following the instant of minimum cavity volume could exceed the resistance of nearby structure. Kornfeld and Suvorov [14] suggested that the bubble collapse near a solid boundary would generate the phenomenon of jet flow due to the nonspherical deformation of the bubble interface. Such an asymmetry causes the side of the bubble that is farther from the solid boundary, to accelerate inward more rapidly, creating a high-speed reentrant microjet directed towards the boundary. Note that this re-entrant jet reaches a high speed quite early in the collapse process and long before the instant of minimum cavity volume. Later, this phenomenon was observed experimentally by Naudé and Ellis [18] before being demonstrated throughout the calculations of Plesset and Chapman [22].

As such, cavitation bubble collapse is a violent process characterized by high pressure pulses and high speed microjets. Repetitive collapses occurring close to solid wall therefore cause local surface fatigue failure and possibly a subsequent detachment of pieces of material. Although this idea is generally accepted to 


\section{Nomenclature}

$c \quad$ coefficient of phase change

$c_{v} \quad$ isochoric heat capacity (J/kg.K)

$c_{p} \quad$ isobaric heat capacity (J/kg.K)

$h_{l v} \quad$ latent heat $(\mathrm{J} / \mathrm{kg})$

$K_{v} \quad$ ratio of the molar mass to the universal gas constant (kg.K/J)

$k \quad$ thermal conductivity (W/m.K)

$\dot{m} \quad$ rate of phase change $(\mathrm{kg} / \mathrm{s})$

$n_{p} \quad$ polytropic volume exponent

$p \quad$ pressure (Pa)

$\mathrm{Pr} \quad$ Prandtl number

$R \quad$ bubble radius ( $\mathrm{m}$ )

$r \quad$ radial coordinate $(\mathrm{m})$

$T$ temperature $\left({ }^{\circ} \mathrm{C}\right)$

$t_{c 4} \quad$ characteristic time (s)

$t_{T C} \quad$ total collapse time $(\mathrm{s})$

$u \quad$ specific internal energy $(\mathrm{J} / \mathrm{kg})$

\section{Subscripts}

$c \quad$ uniform vapor region inside the bubble

$f \quad$ final state (case of a liquid pressure rise)

$g \quad$ non-condensable gas

$i \quad$ bubble interface

$l \quad$ liquid phase

li at the liquid interface

$l_{\infty} \quad$ in the bulk liquid

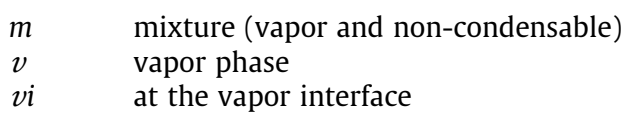

\section{Greek symbols}

$\alpha \quad$ thermal diffusivity $\left(\mathrm{m}^{2} / \mathrm{s}\right)$

$\alpha_{T} \quad$ thermal accommodation coefficient

$\beta \quad$ factor of Florschuetz and Chao

$\Delta T \quad$ saturation temperature rise corresponding to the pres-

$$
\text { sure rise }
$$

$\Delta T^{*} \quad$ reference temperature drop of Stepanoff

$\delta_{T} \quad$ thermal layer thickness (m)

$\varepsilon \quad$ ratio of mixture density to liquid density

$\gamma \quad$ specific heat ratio

$\mu \quad$ dynamic viscosity (Pa.s)

$\rho \quad$ density $\left(\mathrm{kg} / \mathrm{m}^{3}\right)$

$\sigma \quad$ surface tension $\mathrm{N} / \mathrm{m}$

$\Sigma \quad$ Brennen parameter $\left(\mathrm{m} . \mathrm{s}^{-3 / 2}\right)$

Superscripts

* at the saturation conditions

\section{Abbreviations}

sc- $\mathrm{CO}_{2}$ supercritical $\mathrm{CO}_{2}$

lc- $\mathrm{CO}_{2}$ liquid $\mathrm{CO}_{2}$ near the critical point

on the critical point and the sc- $\mathrm{CO}_{2}$, some formulations of bubble dynamics in the literature are first reported. This is to highlight the different mechanisms that contribute to the behavior of the bubble, paving the way to a qualitative evaluation of the bubble dynamics. A model for the bubble dynamics has been proposed to study the bubble collapse in $\mathrm{lc}-\mathrm{CO}_{2}$ under the increase in the liquid pressure.

\section{Theoretical background}

\subsection{The critical point and the supercritical cycle}

The term critical point is used to designate the thermodynamic state at which the properties of gas and liquid phases converge. Indeed, upon temperature and pressure changes along the vaporliquid equilibrium curve, both phases coexist. With temperature

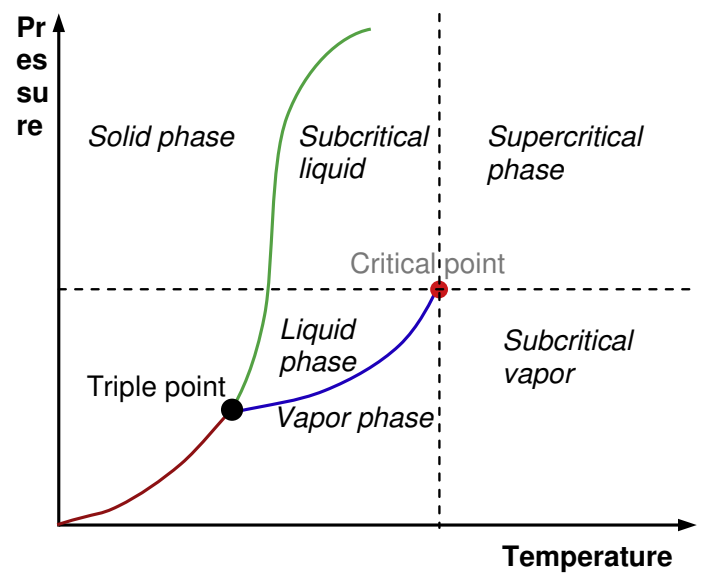

Fig. 1. The pressure-temperature phase diagram. 
increase, the liquid becomes less dense whereas pressure increase makes the vapor phase becomes more dense. As a result, the distinction of liquid and vapor phases becomes less and less pronounced, and then no longer exists. In the end, there is only one homogenous phase in the system. The point that marks the endpoint of the saturation curve (cf. Fig. 1) is named as the critical point. The temperature and pressure at the critical point are called the critical temperature and critical pressure. For $\mathrm{CO}_{2}$, the critical temperature and critical pressure are $30.98^{\circ} \mathrm{C}$ and $7.377 \mathrm{MPa}$, respectively.

The supercritical phase corresponds to the conditions where both temperature and pressure are above those determining the critical point. Since this phase represents a state in which liquid and vapor properties converge, supercritical fluids show common features with vapor and some with liquid. Specifically, the supercritical fluid has densities approaching those of liquid phase and diffusivities and viscosities approaching those of vapor phase. Their physical properties can also be turned to be more liquid-like or more gas-like, by changing the temperature and pressure. These unique behaviors make the supercritical fluid an excellent solvent for various applications. For example, $\mathrm{sc}-\mathrm{CO}_{2}$ has widely been used in the commercial decaffeination of coffee and black tea [17].

The idea of using $\mathrm{sc}-\mathrm{CO}_{2}$ as the working fluid in a thermodynamic cycle was first proposed by Sulzer [29]. Different cycle configurations were introduced and the thermodynamic analysis was carried out in the 1960's in $[6,2,1]$. The sc- $\mathrm{CO}_{2}$ cycle was claimed to avoid most of problems of the Rankine steam and Brayton gas cycles and yet retain many of their advantages $[6,2,5,4]$ : (i) potentially high efficiency thank to the low compression work in the reduced compressibility region near critical point; (ii) smaller size of the turbomachinery resulting from the high density working fluid; (iii) simpler system layout; (iv) less sensitivity of the thermodynamic performance to pressure losses; and ( $v$ ) better match of temperature profile to that of the heat source provided by the fluid in the supercritical region. Over the past decade, growing interest on the sc- $-\mathrm{CO}_{2}$ cycle has been seen through a significant amount of works that have been conducted in view of analyzing these potential advantages for various heat sources. These include low grade waste heat applications [4], hybrid fuel cell systems [24], nuclear reactors including innovative small modular reactors $[26,40]$, next generation nuclear reactors $[5,12,9]$ and fusion reactor concepts [13], and concentrated solar power plants [33]. An overview on the performance of the $\mathrm{sc}-\mathrm{CO}_{2}$ cycle in a large range of heat source temperature can be found in [20].

Generally, a thermodynamic cycle is preferred to reject heat to the cold source at low temperature in view of improving the efficiency. In the original sc- $\mathrm{CO}_{2}$ cycles of Angelino [2], the cooling was performed across the two-phase region and thus the compression started from the liquid region. Later, Dostal [5] reviewed these cycles for the next generation nuclear reactors and suggested switching the compression to the supercritical region for two reasons. Firstly, the cycle heat sink can be adapted to worldwide temperatures and secondly possible cavitation problems with pump can be avoided. If this latter is confirmed to yield no detrimental effects, as promisingly suggested through tests at Sandia National Laboratories, and if cold heat sinks are available, there will remain opportunity to improve the efficiency of the sc- $\mathrm{CO}_{2}$ cycle by cooling the working fluid below the critical temperature (i.e. operating the compressor/pump in the liquid region). Typically, Floyd et al. [8] reported an efficiency gain of 2 points for a $\mathrm{sc}-\mathrm{CO}_{2}$ cycle coupled to a Sodium-cooled Fast Reactor concept.

\subsection{Bubble dynamics}

As mentioned above, the first analysis of bubble dynamics was made by Rayleigh [23]. His theory was developed for a single bubble in an infinite quiescent liquid using the assumption of liquid incompressibility and of negligible surface tension and liquid viscosity. Since then, many researchers have improved this theory by eliminating more and more hypotheses. Plesset [21] extended Rayleigh work by considering the influence of liquid viscosity and surface tension, deriving the well-known Rayleigh-Plesset equation. Later, a more general form was given by Scriven [25] for the case of non-zero ratio of mixture (i.e. vapor and noncondensable gas) density to liquid density as follows (see nomenclature for more details):

$R_{i} \ddot{R}_{i}+\frac{3}{2} \dot{R}_{i}^{2}=\frac{1}{\varepsilon \rho_{l \infty}}\left(p_{m}-p_{l \infty}-\frac{2 \sigma}{R_{i}}-\frac{4 \mu_{l}}{R_{i}} \dot{R}_{i}\right)$

It is important to note that such an equation was derived using the following assumptions: (i) the fraction of dissolved gas and the effect of non-condensable diffusion across the interface are negligible; (ii) the liquid density and other thermal and transport properties of liquid are constant; (iii) the vapor inside the bubble remains at the saturation conditions with respect to the liquid temperature at the bubble interface (i.e. equilibrium phase change assumption); and (iv) the temperature and pressure inside the bubble as well as its contents are always uniform.

In addition, if it is assumed that the non-condensable gas inside the bubble follows a polytropic process characterized by the exponent $n_{p}$, Eq. (1) can be rewritten as follows:

$$
\begin{aligned}
\underbrace{R_{i} \ddot{R}_{i}+\frac{3}{2}}_{(I)} \dot{R}_{i}^{2}= & \underbrace{\frac{p_{l \infty}^{*}-p_{l \infty}}{\varepsilon \rho_{l \infty}}}_{(I I)}+\underbrace{\frac{p_{l i}^{*}-p_{l \infty}^{*}}{\varepsilon \rho_{l \infty}}}_{(I I I)}+\underbrace{\frac{p_{g o}}{\varepsilon \rho_{l \infty}} \frac{T_{l i}}{T_{l \infty}}\left(\frac{R_{o}}{R_{i}}\right)^{3 n_{p}}}_{(I V)} \\
& -\underbrace{\frac{1}{\varepsilon \rho_{l \infty}} \frac{2 \sigma}{R_{i}}}_{(V)}-\underbrace{\frac{1}{\varepsilon \rho_{l \infty}} \frac{4 \mu_{l}}{R_{i}} \dot{R}_{i}}_{(V I)}
\end{aligned}
$$

In Eq. (2), the first term (I) refers to the motion of the bubble interface. The second term (II) is the instantaneous tension or inertial term, which is determined by the conditions of the bulk liquid. The third one $(I I I)$, so-called the thermal term, refers to the change of the saturation pressure $\left(p_{l i}^{*}\right)$ with respect to the change of the temperature at the interface $\left(T_{l i}\right)$. The three last terms, $(I V),(V)$ and $(V I)$ are the contribution of non-condensable gas, the surface tension and liquid viscosity, respectively.

The liquid temperature at the interface varies due to the phase change during the bubble growth or collapse. This was previously explained by Stepanoff [28] through the energy conversion aspect. Accordingly, the production of a volume of vapor in the case of bubble growth requires a quantity of heat. This energy comes from a volume of liquid in the vicinity of the cavity region that is cooled, thereby forming a thermal layer around the bubble (c.f. Fig. 2). The liquid temperature at the interface becomes lower than the bulk liquid temperature. The vapor pressure, assumed to be equal to the saturation pressure at the interface temperature $\left(p_{l i}^{*}\right)$, also decreases from its initial value $\left(p_{l_{\infty}}^{*}\right)$. The thermal term in Eq. (2) is negative and therefore has an impeding effect on the motion of the bubble interface. Similar arguments can also be given in case of bubble collapse, leading to the same conclusion on the effects of the thermal term on the bubble dynamics.

If the contribution of the thermal term is negligible compared to that of the inertial term, the bubble dynamics belongs to the socalled inertially controlled regime. In such a case, the bubble radius is the unique time dependent variable in Eq. (2). This latter is therefore sufficient to describe the dynamics of the bubble interface. Otherwise, the change of the liquid temperature at the bubble interface should be taken into account through the energy equation (i.e. heat conduction equation) for the liquid region. In this case, the bubble dynamics is classified into the thermally controlled regime. Note that even though this regime is named as 

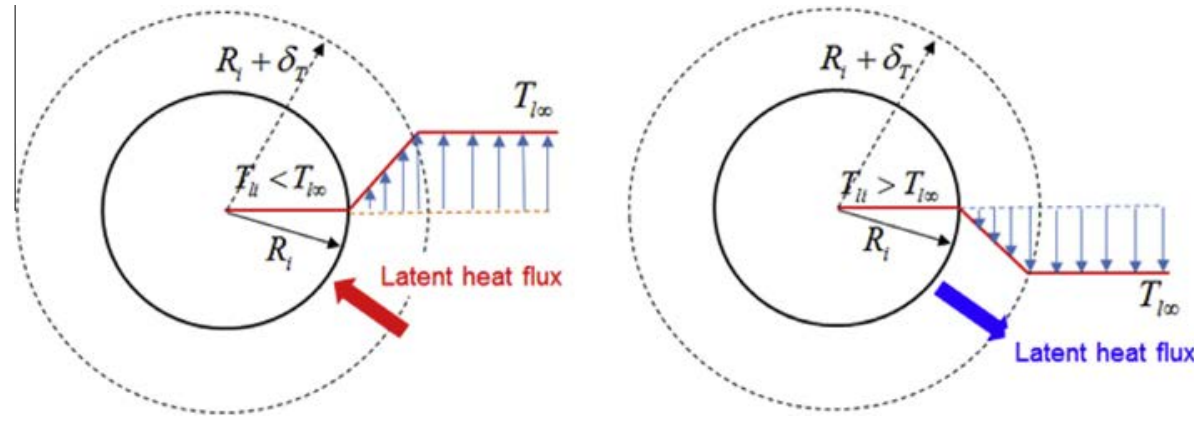

Fig. 2. Thermal boundary layer surrounding the bubble during the growth (left) and collapse (right).

"thermally controlled" in [3], both inertial and thermal terms have an impact on the bubble dynamics.

Different parameters were proposed in the literature to characterize the thermal effects in the bubble dynamics. The simplest one is, perhaps, the reference temperature drop of Stepanoff [28], given as:

$\Delta T^{*}=\frac{\rho_{v} h_{l v}}{\rho_{l} c_{p l}}$

This parameter reflects the aforementioned explanation of the temperature change at the interface. It can be interpreted as the temperature drop to be applied to a given volume of liquid in order to get sufficient energy to produce the same volume of vapor. The smaller this reference temperature drop is, the less important the thermal effects have on the bubble dynamics.

In the case of bubble collapse, Florschuetz and Chao [7] suggested the use of the following factor to characterize the thermal effects:

$\left.\beta=\left[\frac{\rho_{l_{\infty}} c_{p l_{\infty}} \Delta T}{\rho_{v} h_{l v}}\right]^{2} \frac{\alpha_{l}}{R_{o}} \frac{\rho_{l_{\infty}}}{p_{l_{\infty} f}-p_{l_{\infty}}^{*}}\right)$

The following limits can be used to evaluate the thermal effects: $\beta>10$ : thermal term is negligible; $\beta<0.05$ : inertial term is negligible; $0.05<\beta<10$ : both inertial and thermal terms should be retained.

In the case of a collapse/growth under a step increase/decrease in the liquid pressure, Brennen [3] provided the following parameter to characterize the thermal effects:

$\sum\left(T_{\infty}\right)=\frac{h_{l v}^{2} \rho_{v}^{2}}{\varepsilon \rho_{l \infty}^{2} c_{p l} T_{l \infty} \alpha_{l}^{1 / 2}}$

The greater this parameter is, the higher the contribution of thermal effects to bubble dynamics is. He also suggested using the following critical time to represent the time necessary for the thermal term to reach a comparable order of magnitude with the inertial term during the bubble collapse:

$t_{c 4}=\left(R_{o} / \Sigma\right)^{2 / 3}$

This formulation can only be valid if the critical time is smaller than the total collapse time in the absence of the thermal effects. This was proposed by Rayleigh [23], assumed that the effects of surface tension and non-condensable gas are negligible, as follows:

$\left.t_{T C}=0.915 \cdot \frac{\rho_{l_{\infty} R_{o}^{2}}}{p_{l \infty f f}-p_{l_{\infty}}^{*}}\right)^{1 / 2}$

If $t_{c 4} \ll t_{T c}$, the bubble dynamics will be initially dominated by the thermal term and thus the bubble collapse will become much less violent.
Table 1

Calculation of parameters characterizing the thermal effects in the bubble dynamics.

\begin{tabular}{lllll}
\hline & $\mathrm{H}_{2} \mathrm{O}$ & $\mathrm{H}_{2} \mathrm{O}$ & $\mathrm{N}_{2}$ & $\mathrm{CO}_{2}$ \\
\hline$T_{l \infty}\left({ }^{\circ} \mathrm{C}\right)$ & 20 & 93.3 & -190 & 25 \\
$\rho_{v}\left(\mathrm{~kg} / \mathrm{m}^{3}\right)$ & 0.017 & 0.476 & 8.28 & 242.8 \\
$\rho_{l \infty}\left(\mathrm{kg} / \mathrm{m}^{3}\right)$ & 998.16 & 963.05 & 779.08 & 710.32 \\
$\varepsilon$ & 1.00 & 1.00 & $9.89 \mathrm{e}-01$ & $6.58 \mathrm{e}-01$ \\
$h_{l v}(\mathrm{~kJ} / \mathrm{kg})$ & 2453.53 & 2273.99 & 191.26 & 119.56 \\
$c_{p l}(\mathrm{~kJ} / \mathrm{kg} . \mathrm{K})$ & 4.19 & 4.21 & 2.12 & 6.47 \\
$\alpha_{l}\left(\mathrm{~m}^{2} / \mathrm{s}\right)$ & $1.45 \mathrm{e}-07$ & $1.67 \mathrm{e}-07$ & $8.10 \mathrm{e}-08$ & $1.76 \mathrm{e}-08$ \\
$\Delta T^{*}\left({ }^{\circ} \mathrm{C}\right)$ & 0.01 & 0.27 & 0.96 & 6.31 \\
$\Sigma\left(\mathrm{m} / \mathrm{s}^{3 / 2}\right)$ & 3.90 & $2.01 \mathrm{e}+03$ & $8.33 \mathrm{e}+04$ & $9.92 \mathrm{e}+06$ \\
\hline
\end{tabular}

Table 2

Calculation of characteristic parameters of the thermal effects during the bubble collapse.

\begin{tabular}{lllll}
\hline & $\mathrm{H}_{2} \mathrm{O}$ & $\mathrm{H}_{2} \mathrm{O}$ & $\mathrm{N}_{2}$ & $\mathrm{CO}_{2}$ \\
\hline$R_{o}(\mathrm{~m})$ & 0.001 & 0.001 & 0.001 & 0.001 \\
$T_{l_{\infty}}\left({ }^{\circ} \mathrm{C}\right)$ & 20 & 93.3 & -190 & 25 \\
$p_{l_{\infty} f}=1.02 p_{l_{\infty}}^{*}(\mathrm{MPa})$ & $2.44 \mathrm{e}-03$ & $8.10 \mathrm{e}-02$ & $1.94 \mathrm{e}-01$ & 6.56 \\
$t_{T C}(\mathrm{~s})$ & $1.1 \mathrm{e}-04$ & $1.9 \mathrm{e}-04$ & $7.4 \mathrm{e}-05$ & $6.7 \mathrm{e}-05$ \\
$t_{c 4}(\mathrm{~s})$ & $4.0 \mathrm{e}-03$ & $6.3 \mathrm{e}-05$ & $5.2 \mathrm{e}-06$ & $2.2 \mathrm{e}-07$ \\
$t_{c 4} / t_{T C}$ & 36.36 & 0.33 & 0.07 & 0.003 \\
$\Delta T\left({ }^{\circ} \mathrm{C}\right)$ & 70.36 & 6.70 & 5.00 & 0.86 \\
$\beta$ & 1.34 & $1.39 \mathrm{e}-02$ & $7.33 \mathrm{e}-05$ & $2.23 \mathrm{e}-08$ \\
\hline
\end{tabular}

\section{Analytical evaluation of the bubble dynamics in Ic- $\mathrm{CO}_{2}$}

The contribution of the thermal effects to the bubble dynamics can be qualitatively evaluated through the aforementioned characteristic parameters. Table 1 reports the values of the reference temperature drop of Stepanoff (c.f. Eq. (3)) and the parameter of Brennen (c.f. Eq. (5)) for bubbles in different liquids and temperature conditions. Also given in this table are the thermodynamic properties of fluids that are required for the calculation of these parameters. In addition to the case of interest, i.e. a $\mathrm{CO}_{2}$ bubble at $25^{\circ} \mathrm{C}$, the remaining ones have been given to provide a qualitative comparison since their cavitation effects are well-known or were addressed in the past. The $\mathrm{H}_{2} \mathrm{O}$ bubble at ambient temperature can be referred to as the case of cavitation in water, which commonly leads to detrimental effects. The collapse of the $\mathrm{H}_{2} \mathrm{O}$ bubble at $93.3^{\circ} \mathrm{C}$ was numerically investigated by Florschuetz and Chao [7], who demonstrated significant thermal effects leading to a slow contraction of the bubble. The $\mathrm{N}_{2}$ bubble at $-190{ }^{\circ} \mathrm{C}$ could be used to characterize the cavitation in the liquid $\mathrm{N}_{2}$. This is known as cryogenic cavitation and was previously demonstrated to be significantly affected by the thermal effects (see, e.g., [32].

Both parameters of Stepanoff and Brennen show a similar trend in the increasing significance of the thermal effects. These range from the $20{ }^{\circ} \mathrm{C} \mathrm{H}_{2} \mathrm{O}$ bubble, to the $93.3^{\circ} \mathrm{C} \mathrm{H}_{2} \mathrm{O}$ bubble, the 
Table 3

Decomposition of the parameter of Brennen.

\begin{tabular}{lllll}
\hline & $\mathrm{H}_{2} \mathrm{O}$ & $\mathrm{H}_{2} \mathrm{O}$ & $\mathrm{N}_{2}$ & $\mathrm{CO}_{2}$ \\
\hline$T_{l \infty}\left({ }^{\circ} \mathrm{C}\right)$ & 20 & 93.3 & -190 & 25 \\
$\rho_{v}^{2} /\left(\varepsilon \rho_{l \infty}^{2}\right)$ & $3.0 \mathrm{e}-10$ & $2.5 \mathrm{e}-07$ & $1.1 \mathrm{e}-04$ & $1.8 \mathrm{e}-01$ \\
$h_{l v}^{2} /\left(c_{p l}^{2} T_{l \infty}^{2}\right)$ & 4.0 & 2.2 & 1.2 & $3.8 \mathrm{e}-03$ \\
$\left(c_{p l} T_{l \infty}\right) / \alpha_{l}^{1 / 2}$ & $3.2 \mathrm{e}+09$ & $3.8 \mathrm{e}+09$ & $6.2 \mathrm{e}+08$ & $1.5 \mathrm{e}+10$ \\
\hline
\end{tabular}

$-190{ }^{\circ} \mathrm{C} \mathrm{N}_{2}$ bubble, and to the $25^{\circ} \mathrm{C} \mathrm{CO}_{2}$ bubble. The $20^{\circ} \mathrm{C} \mathrm{H}_{2} \mathrm{O}$ bubble features a negligible reference temperature drop, explaining the predominance of the inertial effects and thus the violent collapse. The $25^{\circ} \mathrm{C} \mathrm{CO}_{2}$ bubble dynamics features the strongest influence of the thermal effects.

To make a clearer statement in the case of bubble collapse, let's consider these four bubbles at an initial radius of $1 \mathrm{~mm}$ under a step increase of $2 \%$ in the liquid pressure (c.f. Table 2). The choice of such a small variation is to maintain the liquid properties, especially those of $\mathrm{CO}_{2}$, constant, as is the assumption upon which these characteristic parameters were derived. The critical time during the collapse ( $t_{c 4}$ in Eq. (6)) is given in comparison with the total collapse time ( $t_{T C}$ in Eq. (7)). The calculation results show that, except the case of the $\mathrm{H}_{2} \mathrm{O}$ bubble at $20^{\circ} \mathrm{C}$, the thermal term will very soon reach a magnitude that can hinder the effects of the inertial term during the contraction of the bubble. The $\beta$-factor of Florschuetz and Chao [7] is also given. Its very small order of magnitude for the $\mathrm{CO}_{2}$ bubble case compared to the other cases also suggests the strong implications of the thermal effects.

With the significant dominance of the thermal effects, the dynamics of the $\mathrm{CO}_{2}$ bubble should be characterized by a very slow motion of the interface. Indeed, while the thermal regime is already connected to a slower time square root asymptotic dynamic compared to the time squared dynamic of the inertia regime [3], this asymptotic rate is inversely proportional to $\Sigma$. For lc- $\mathrm{CO}_{2}$, the rate is therefore 2 orders of magnitude lower than for the above $\mathrm{N}_{2}$ case, which was already considered as paradigmatic of a slow thermal regime.

One can therefore expect that there would be no high pressure wave release during the bubble collapse. This promisingly suggests that cavitation damage commonly found in water would not be experienced in the case of cavitation in $\mathrm{lc}-\mathrm{CO}_{2}$.

In order to further understand which properties of $\mathrm{CO}_{2}$ near the critical point are responsible for the significance of the thermal effects, the parameter of Brennen has been decomposed through different terms as follows:

$\Sigma\left(T_{\infty}\right)=\frac{h_{l v}^{2} \rho_{v}^{2}}{\varepsilon \rho_{l \infty}^{2} c_{p l} T_{l \infty} \alpha_{l}^{1 / 2}}=\left(\frac{\rho_{v}^{2}}{\varepsilon \rho_{l \infty}^{2}}\right)\left(\frac{h_{l v}^{2}}{c_{p l}^{2} T_{l \infty}^{2}}\right)\left(\frac{c_{p l} T_{l \infty}}{\alpha_{l}^{1 / 2}}\right)$

The order of magnitude of each term is reported in Table 3. This decomposition clearly indicates that it is the high ratio of vapor to liquid density near the critical point that contributes to form a very high characteristic parameter in the case of the $\mathrm{CO}_{2}$ bubble compared to the other cases. Other properties near the critical point such as the small heat latent and thermal diffusivity also impact the parameter of Brennen but their effects are less pronounced.

Finally, it is important to note that this numerical application should only be seen as very indicative since they are connected to some previously mentioned assumptions. In addition to the one of constant liquid properties, the consideration of a uniform vapor bubble is, as discussed in the following section, no longer appropriate for $\mathrm{CO}_{2}$ near the critical point

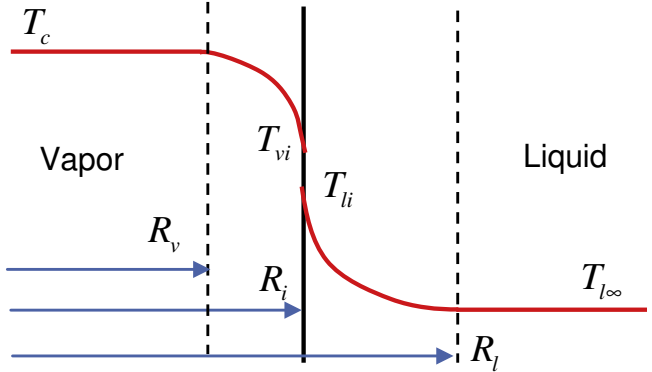

Fig. 3. Schematic of the temperature profiles developed inside and outside bubble.

\section{Simulations of the bubble collapse in lc-CO2}

\subsection{Assumptions}

The following sections list the model assumptions which are applied to a bubble supposed spherical. This latter hypothesis has been adopted in numerous works [23,21,25,30] of which the contribution to the enlightenment of the bubble dynamics is significant. [11] has shown, using high-speed shadow photography on a laser-induced cavitation bubble, that while the bubble crosssection is no longer spherical after the first rebound, this assumption is relevant before the collapse. As a consequence, this simplification is not seen to have strong implications on the main conclusion of the current work which is bounded by a dominant thermal regime.

\subsubsection{Thermal layer in the vapor region}

Bubble dynamics is commonly studied by considering only the liquid flow equation. The gas flow is actually excluded under the assumption of a uniform bubble: uniform temperature, pressure and density. The validity of the uniform temperature assumption depends on the respective characteristic time scale of the heat diffusion through liquid and vapor regions: the thermal diffusivity of the vapor has to be much greater than that of the liquid [34]. Indeed, the thermal diffusivity of a substance represents its heat diffusion capacity: a higher thermal diffusivity leads to a shorter characteristic time of heat diffusion. As such, the temperature profile will become uniform earlier.

The above consideration can be no longer relevant in the case of significant temperature increase inside the bubble during a very short time, for example at the final stages of an inertiallycontrolled bubble collapse. In such a situation, there should be a temperature gradient formed inside the bubble, in addition to the one in the liquid region (cf. Fig. 3). Note that this inner thermal layer was previously considered in the work of Fujikawa and Akamatsu [10] in order to capture the significant increase in the vapor temperature at the final stages of bubble collapse in water.

This treatment becomes essential in the case of a bubble in lc$\mathrm{CO}_{2}$, even at the early stages of bubble growth or collapse, due to the convergence of fluid and vapor properties. As reported in Table 4 , the thermal diffusivity of liquid and vapor $\mathrm{CO}_{2}$ at $25^{\circ} \mathrm{C}$ have the same order of magnitude, which is not the case for a water bubble. It means that there will be a thermal layer developing inside the $\mathrm{CO}_{2}$ bubble with a temperature gradient equivalent to that of the thermal layer surrounding the bubble. Accordingly, the heat transfer at the interface of the $\mathrm{CO}_{2}$ bubble takes place in both liquid and vapor regions during its collapse and growth.

\subsubsection{Non-equilibrium phase change}

The non-equilibrium phase change means that the vapor is no longer maintained at the saturation conditions with respect to the liquid temperature at the interface: 
Table 4

Comparison of thermal diffusivity in liquid and in vapor of $\mathrm{CO}_{2}$ and $\mathrm{H}_{2} \mathrm{O}$.

\begin{tabular}{lll}
\hline & $\alpha_{v}\left(\mathrm{~m}^{2} / \mathrm{s}\right)$ & $\alpha_{l}\left(\mathrm{~m}^{2} / \mathrm{s}\right)$ \\
\hline $\mathrm{H}_{2} \mathrm{O}\left(20^{\circ} \mathrm{C}\right)$ & $5.5 \mathrm{e}-5$ & $1.4 \mathrm{e}-8$ \\
$\mathrm{CO}_{2}\left(25^{\circ} \mathrm{C}\right)$ & $2.3 \mathrm{e}-8$ & $1.8 \mathrm{e}-8$ \\
\hline
\end{tabular}

$\left\{\begin{array}{l}T_{v i} \neq T_{l i} \\ p_{v i} \neq p_{l i}^{*}\end{array}\right.$

Under such a situation, the phase change takes place at a finite rate and can be determined through the state variables of the liquid and vapor phases at the interface as follows [30]:

$\dot{m}=c \sqrt{\frac{K_{v}}{2 \pi}}\left(\frac{p_{l i}^{*}}{\sqrt{T_{l i}}}-\frac{p_{v i}}{\sqrt{T_{v i}}}\right)$

in which the coefficient of phase change $c$ is a time independent parameter. This model is based on a symmetrical treatment for liquid and gas phases (that could be considered as relevant nearby the critical point due to the closeness of the properties for both phases) and is assuming a perfect gas law for both phases. While the c coefficient should be understood as a fitting of experimental data that could accommodate the fluid actual thermodynamic, it is merely introduced in the current work for the sake of generality as the model will be benchmarked with a case study where this assumption is relevant. Indeed, we will see that the impact of such a refinement on the $\mathrm{CO}_{2}$ bubble dynamics is seen as negligible since the state of vapor at the interface is predicted to be very close to the equilibrium state with the liquid.

\subsubsection{Assumption of constant liquid properties}

The Rayleigh equation of bubble dynamics and most of its generalized forms (e.g. Rayleigh-Plesset, Scriven...) were developed using the assumption of constant liquid density. This latter is no longer valid in $1 \mathrm{c}-\mathrm{CO}_{2}$ due to the large change of the density with respect to the temperature and pressure variations. As such, the fluid density is a function of both time and space (radial coordinates), preventing one from obtaining a unique time differential equation that describes the motion of the bubble interface. Accurate solutions of this problem can only be achieved by considering a complicated system of partial differential equations that involves time and space dependent variables. Such an approach is disregarded in the frame of this preliminary investigation. For the case studies reported hereafter, the density change is limited below $7 \%$. Hence, the constant density assumption still remains relevant.

Other liquid properties such as the surface tension and viscosity were also considered as constant. Actually, the effects of their variation on the motion of the bubble interface can be negligible, except in the final stages of a violent collapse. Indeed, it is only under this circumstance that the inward velocity is very high and the bubble radius is sufficiently small making the contributions of the surface tension and liquid viscosity more pronounced (see terms $V$ and $V I$ in Eq. (2)). Since the collapse of a $\mathrm{CO}_{2}$ bubble has been forecasted to be very slow, these properties can be relevantly assumed to be invariant without having implications on the $\mathrm{CO}_{2}$ bubble dynamics. In addition to these assumptions, it is supposed that there is no non-condensable gas and that the vapor density is uniform inside the bubble in order to simplify the equations.

\subsection{Mathematical model}

In the bubble dynamics model for $\mathrm{CO}_{2}$ near the critical point, the thermal layers inside and surrounding the bubble are both considered, together with a temperature discontinuity at the interface as illustrated in Fig. 3. As such, the problem has 7 unknowns: 3 radial coordinates $\left(R_{v}, R_{i}\right.$ and $\left.R_{l}\right), 3$ temperature variables $\left(T_{c}, T_{v i}\right.$ and $T_{l i}$ ), and one more state variable to fully define, together with $T_{c}$, the state of the uniform vapor region. For this latter, the density $\left(\rho_{c}=\rho_{v}\right)$ is chosen. The following subsections report the 7 equations that are involved in this problem.

\subsubsection{Equation of bubble dynamics}

The equation of Scriven [25] for the case of non-zero ratio of vapor to liquid density is used to describe the motion of the bubble interface (cf. Eq. (1)).

\subsubsection{Energy equation for the liquid region}

For $\mathrm{CO}_{2}$ near the critical point, the specific heat capacity is no longer a relevant indicator of the enthalpy change, and thus the energy equation should be written for the internal energy as follows:

$\int_{R_{i}}^{\infty} \rho_{l} r^{2}\left(\frac{\partial u_{l}}{\partial t}+v_{l} \frac{\partial u_{l}}{\partial r}\right) d r=\int_{R_{i}}^{\infty} \frac{\partial}{\partial r}\left(r^{2} k_{l} \frac{\partial T_{l}}{\partial r}\right)$

The internal energy can be determined from a couple of two state variables, for example density and temperature. The former is assumed to be constant in the whole liquid region, and thus:

$u_{l}(r)=u\left(\rho_{l \infty}, T_{l}(r)\right)$

The liquid temperature in the thermal layer $\left(R_{i} \leqslant r \leqslant R_{l}\right)$ is approximated through a quadratic distribution, as proposed by Theofanous et al. [30,31]:

$T_{l}=T_{l \infty}+\left(T_{l i}-T_{l \infty}\right)\left(\frac{R_{l}-r}{R_{l}-R_{i}}\right)^{2}$

Note that such a profile is actually based on an assumption of low thermal layer thickness compared to the bubble radius and so is invalid during final stages of the collapse. In the absence of rebounds, it was found to reproduce adequately the experimental results [15]. Both validity bounds are seen as congruent with the current framework.

The above energy equation can be integrated, leading to the following form:

$$
\begin{aligned}
\rho_{l \infty} \int_{R_{i}}^{R_{l}} r^{2}\left(\frac{\partial u_{l}}{\partial t}+v_{l} \frac{\partial u_{l}}{\partial r}\right) d r & =\int_{R_{i}}^{R_{l}} \frac{\partial}{\partial r}\left(r^{2} k_{l} \frac{\partial T_{l}}{\partial r}\right) \\
& =2 k_{l} \frac{T_{l i}-T_{l \infty}}{R_{l}-R_{i}} R_{i}^{2}
\end{aligned}
$$

in which the velocity of the liquid flow is given as:

$v_{l}(r)=\left(\dot{R}_{i}-\dot{m} / \rho_{l i}\right) R_{i}^{2} / r^{2}$

\subsubsection{Energy equation for the inner thermal layer}

The inner thermal layer is treated in a same way as the thermal layer outside the bubble, i.e. using the assumption of quadratic temperature distribution, leading to the following energy equation:

$\rho_{v} \int_{R_{v}}^{R i} r^{2}\left(\frac{\partial u_{v}}{\partial t}+v_{v} \frac{\partial u_{v}}{\partial r}\right) d r=-2 k_{v} \frac{T_{v i}-T_{c}}{R_{v}-R_{i}} R_{i}^{2}$

The velocity of the vapor flow is assumed to be a linear function of radial coordinate reducing from the interface towards the bubble center [10]:

$v_{v}(r)=\left(\dot{R}_{i}-\dot{m} / \rho_{v i}\right) r / R_{i}$ for $R_{v}<r<R_{i}$

\subsubsection{Energy equation for the vapor region}

On the basis of the first law of thermodynamics, the vapor energy equation for the bubble including the uniform and the thermal layer regions reads: 


$$
\begin{aligned}
& \frac{1}{3} \frac{d}{d t}\left(\rho_{v} R_{v}^{3} u_{c}\right)+\frac{d}{d t} \int_{R_{v}}^{R_{i}} r^{2} \rho_{v} u_{v}(r) d r \\
& \quad=R_{i}^{2}[\underbrace{-p_{v i} \dot{R}_{i}}_{(I)}+\underbrace{k_{v}\left(\frac{\partial T_{v}}{\partial r}\right)_{R_{i}}}_{(I I)}+\underbrace{\dot{m} u_{v i}-c \sqrt{\frac{K_{v}}{2 \pi}} \frac{p_{l i}^{*}}{\sqrt{T_{l i}}}\left(u_{l i}^{*}-u_{v i}\right)}_{(I I I)}]
\end{aligned}
$$

The left hand side of Eq. (18) represents the change of internal energy inside the bubble, including both uniform and thermal layer regions. The first term on the right hand side is the pressure work connected to the volume change; the second term is the conductive heat supplied to (or evacuated from) the vapor region across the interface; and the third term is the internal energy associated with the mass flux of phase change (see, e.g., [30], for a detailed development).

\subsubsection{Continuity equation for the bubble interface}

The continuity equation at the bubble interface reads:

$\rho_{v} \dot{R}_{i}+(1 / 3) \dot{\rho}_{v} R_{i}=\dot{m}$

where the rate of phase change, $\dot{m}$, is calculated from Eq. (10).

\subsubsection{Energy equation for the bubble interface}

This equation correlates the heat fluxes evacuating from (or coming to) the bubble interface to the rate of phase change as follows:

$-2 k_{l} \frac{T_{l i}-T_{l \infty}}{R_{l}-R_{i}}+2 k_{v} \frac{T_{v i}-T_{c}}{R_{v}-R_{i}}=\dot{m} h_{l v}$

The latent heat is a function of the liquid temperature at the interface:

$h_{l v}=h_{l v}\left(T_{l i}\right)$

\subsubsection{Temperature discontinuity at the interface}

The temperature discontinuity between the liquid and vapor regions at the bubble interface is determined as follows [10]:

$T_{v i}=T_{l i}-\frac{\left(2-0.827 \alpha_{T}\right) \gamma_{v i} \mu_{v}}{\left(\gamma_{v}-1\right) \alpha_{T} \operatorname{Pr}_{v} \rho_{v i}}\left(\frac{2 \pi K_{v}}{T_{l i}}\right)^{1 / 2}\left(\frac{\partial T_{v}}{\partial r}\right)_{r=R_{i}(t)}$

in which $\alpha_{T}$ is the thermal accommodation coefficient, $\operatorname{Pr}_{v}$ is the Prandtl number of the vapor phase. Note that the thermal accommodation coefficient is the probability for a vapor molecule striking the liquid-vapor interface to come into thermal equilibrium with the liquid before being diffusively reflected [36].

The set, Eqs. (1), (14), (16), (18), (19), (20), (22), of seven nonlinear, ordinary differential equations has been implemented in Matlab (which solver is implicit and features a relative tolerance on scalars that is inferior to $1 \mathrm{E}-3$ ). It is important to note that all thermodynamic properties involved in these equations (i.e. $\rho, u$, $p^{*}$ and $h_{l v}$ ) are calculated from the Span-Wagner equation of state [27]. The latter is expressed in the form of the specific Helmholtz free energy featuring explicitly the gap to the ideality (with density and temperature as two dependent variables). It is considered as the most reliable mean of describing $\mathrm{CO}_{2}$ properties and is implemented in the NIST database for an accurate use in a wide range of scientific and engineering applications.

\subsection{Model benchmark}

In order to gain a first qualification of the above model, a benchmark has been performed with a previous investigation of bubble collapse in the liquid sodium reported in [31]. In this reference work, a uniform bubble is assumed; in other words, the thermal layer inside the bubble is neglected. The schematic of the temperature change across the bubble interface is illustrated in Fig. 4.

In this configuration, the inner radius of the vapor thermal layer comes close to the bubble interface $\left(R_{v} \approx R_{i}\right)$ and the vapor temperature at the interface is close to the vapor temperature of the uniform vapor region $\left(T_{v i} \approx T_{c}=T_{v}\right)$. As such, there remain only 5 unknowns for this problem. Accordingly, the energy equation for the inner thermal layer (17) and the temperature discontinuity Eq. (22) are excluded from the model. In addition, the energy equations for the bubble interface and the vapor region are reduced as follows (see [31] for more details):

$-2 k_{l} \frac{T_{l i}-T_{l \infty}}{R_{l}-R_{i}}=\dot{m} h_{l v}$

$c_{v v} K_{v} \frac{R_{i}}{T_{v}} \frac{d T_{v}}{d t}=-3 \frac{d R_{i}}{d t}+3 c \sqrt{\frac{K_{v}}{2 \pi}} c_{v v} \frac{p_{l i}^{*}}{p_{v}}\left(\frac{T_{l i}-T_{v}}{\sqrt{T_{l i}}}\right)$

Simulations have been performed for the collapse of a sodium bubble of $6.76 \mathrm{~mm}$ initial radius. The bubble is initially at rest in an infinite liquid domain at a temperature of $857^{\circ} \mathrm{C}$. The liquid pressure is then increased linearly, from an initial value of $0.8 \mathrm{~atm}$ to $1 \mathrm{~atm}$ in $1 \mathrm{~ms}$, and is then maintained constant.

The simulation results are reported in Fig. 5 for different values of the coefficient of phase change $c$ and show a very good agreement to the results obtained in [31] (cf. Fig. 6). It demonstrates that the behavior of the bubble collapse is strongly dependent on the coefficient of phase change. The three values of $c(0.01,0.1$ and 1.0) are, as mentioned in the reference work, chosen to cover the range of acceptable values for the phase change coefficient. For $c=1.0$, the contraction of the bubble interface terminates with the peaks of temperature and pressure and is then followed by the rebound, i.e. the growth of the bubble. For the remaining cases, the bubble exhibits a monotonic mode of collapse.

\subsection{Simulation results and discussions}

The model is applied to study the bubble collapse in $\mathrm{lc}-\mathrm{CO}_{2}$. A bubble of initial radius $1 \mathrm{~mm}$ in an infinite liquid domain at a temperature of $25^{\circ} \mathrm{C}$ has been considered. The liquid pressure is increased linearly, from an initial value of $6.436 \mathrm{MPa}$, by $2 \%$ in $1 \mathrm{~ms}$, and is then maintained constant. The rate of the pressure rise is based on the compressor case [20] and the perturbation amplitude leads to a density increase of around $1 \%$ which is seen as sufficiently small to assure the validity of the bubble dynamics equation. At these conditions, the coefficient of phase change and the thermal accommodation coefficient (c.f. Eq. (22)) for $\mathrm{CO}_{2}$ are set at 0.4 and 0.6 respectively [35].

The simulation results are reported in Figs. 7 and 8 for the calculation times of 2 and $30 \mathrm{~ms}$, respectively. These figures show time dependent plots of bubble radius $\left(R_{i}\right)$, of thickness of the inner and outer thermal layers ( $\delta_{T, \text { inner }}$ and $\delta_{T, \text { outer }}$ ), of vapor temperature in the uniform region $\left(T_{c}\right)$, of liquid temperature at the interface $\left(T_{l i}\right)$, of temperature discontinuity at the interface $\left(T_{v i}-T_{l i}\right)$, of vapor pressure inside the bubble and liquid pressure at the inter-

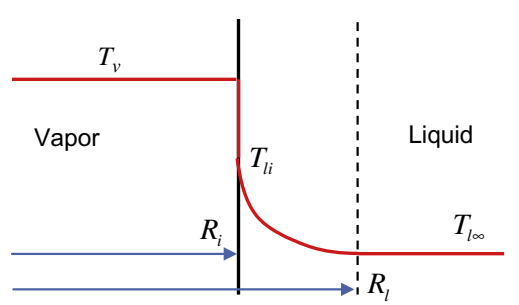

Fig. 4. Schematic of the unique temperature profile developed outside a bubble. 

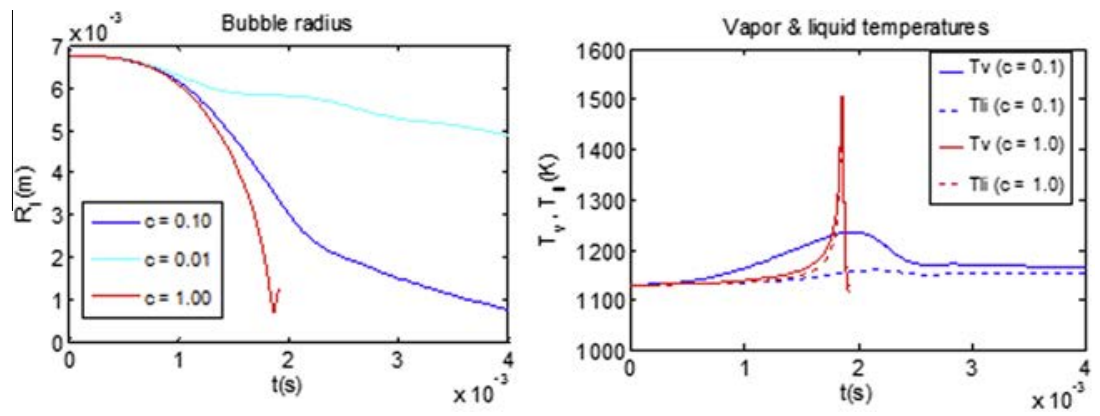

Fig. 5. Results of the bubble collapse in the liquid sodium using the above model.
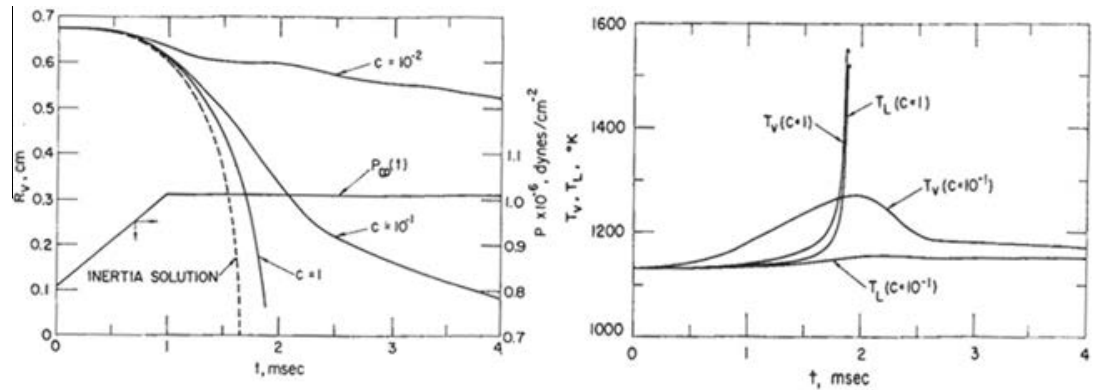

Fig. 6. Simulation results of the bubble collapse in the liquid sodium reported in [31].
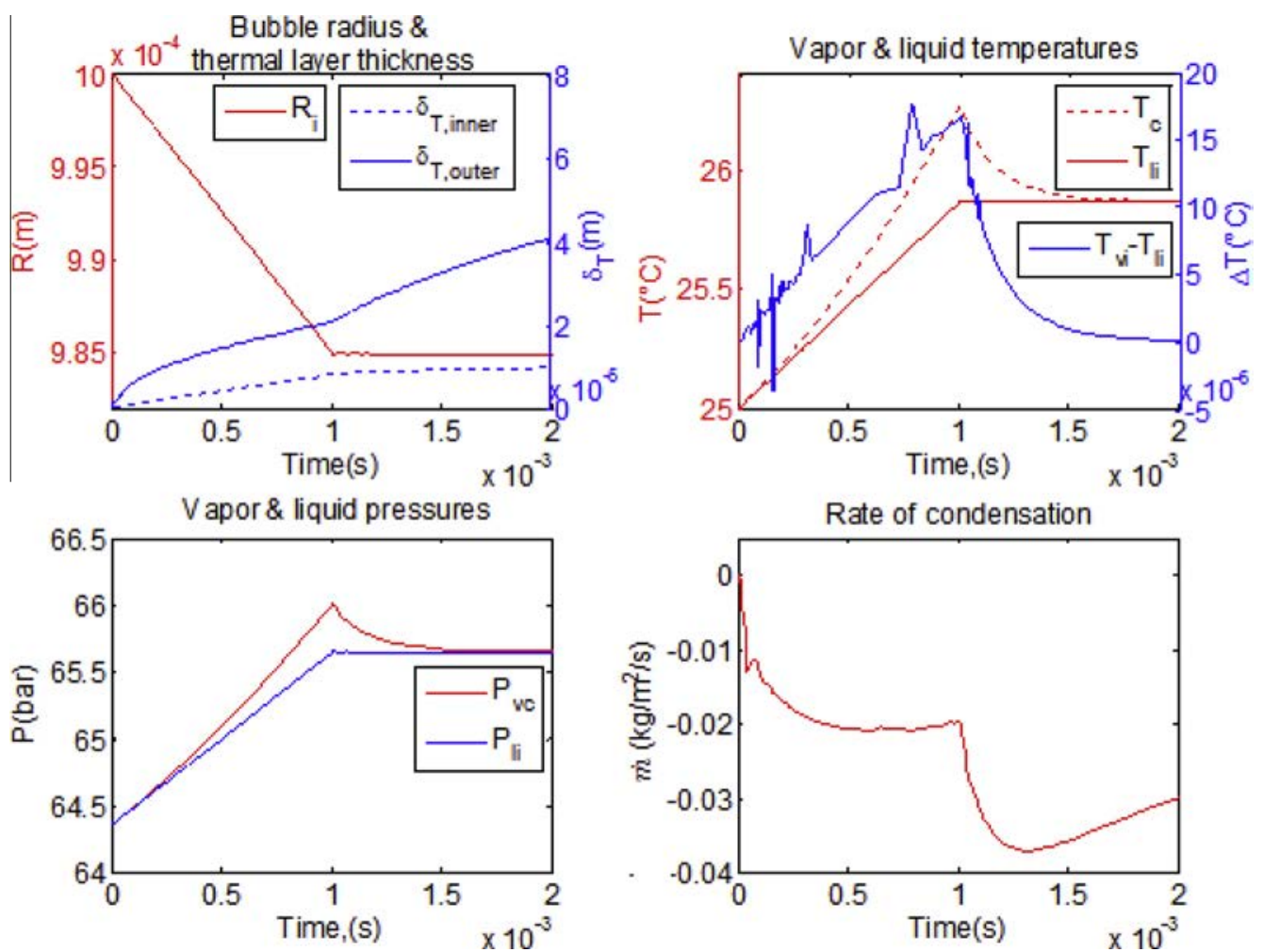

Fig. 7. Results of the $\mathrm{CO}_{2}$ bubble collapse under a $2 \%$ linear increase in the liquid pressure in $1 \mathrm{~ms}$ for a calculation time of $2 \mathrm{~ms}$.

face $\left(p_{v c}\right.$ and $\left.p_{l i}\right)$, and of rate of phase change $(\dot{m})$. Note that this latter has negative value in the case of condensation and positive value in the case of vaporization.

Overall, the temperature discontinuity at the interface is small (around $1 \mathrm{E}-5^{\circ} \mathrm{C}$ ), indicating that the vapor at the interface is close to the saturation state. In other words, the impact of the non-equilibrium assumption on the $\mathrm{CO}_{2}$ bubble dynamic appears of low orders so that performing a sensitivity study on the $c$ parameter was not further considered. In addition, the liquid temperature and pressure at the bubble interface increase linearly with the liquid pressure during the first $1 \mathrm{~ms}$ before attaining constant values. As such, the vapor state changes almost instantaneously, suggest- 

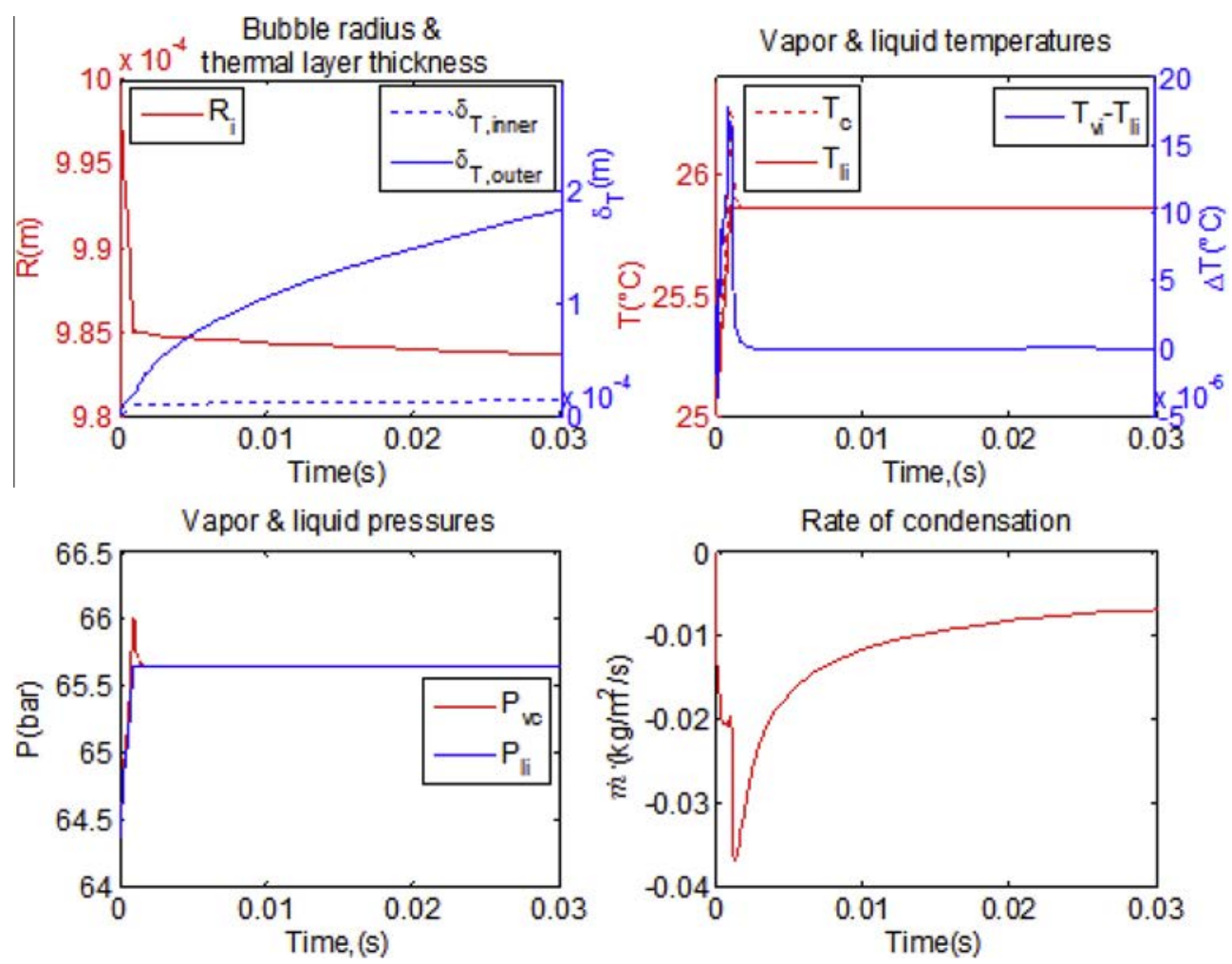

Fig. 8. Results of the $\mathrm{CO}_{2}$ bubble collapse under a $2 \%$ linear increase in the liquid pressure in $1 \mathrm{~ms}$ for a calculation time of $30 \mathrm{~ms}$

ing a rapid increase in the thermal term to equalize the liquid pressure rise. Similarly, the radius decreases linearly with time before reaching a regime featured by a very slow contraction of the bubble.

Besides, the temperature difference across the inner thermal layer has the same order of magnitude as that of the outer thermal layer. This is because of the high energy accumulated inside the bubble during its compression (c.f. Eq. (18)). Hence, both heat fluxes from the vapor region to the interface (inner heat flux) and from the interface to the liquid region (outer heat flux) have equal contribution to the bubble dynamics, by directly resulting in the rate of phase change (see Eq. (20)). The evolution of the rate of phase change, for example as shown in Fig. 7, is connected to the state change of the vapor inside the bubble: during the first $1 \mathrm{~ms}$, under the liquid pressure rise, the heat flux from the vapor increases and impedes the condensation rate; this flux, however, decreases after $1 \mathrm{~ms}$ due to the steadiness of the liquid pressure, thereby leading to the increase in the condensation rate.

The impact of both heat fluxes on the phase change suggests that if the liquid pressure rise is maintained longer (to increase the energy accumulated inside the bubble), the inner heat flux will possibly exceed the outer heat flux. If this is the case, it is vaporization instead of condensation that will take place at the interface. To verify this prediction, an increase in the liquid pressure of $5 \%$ during $2.5 \mathrm{~ms}$ (i.e. the same rate of pressure rise) is considered. Note that the density increase is below 3\%, and thus is consistent with the model assumption. The simulation results are given in Figs. 9 and 10. As expected, the rate of phase change becomes positive near $2.5 \mathrm{~ms}$, when the temperature of the uniform vapor region almost reaches its maximum. After $2.5 \mathrm{~ms}$, this temperature decreases; the phase change returns to condensation with an increasing rate that attains its second maximum at around $5 \mathrm{~ms}$.
If the collapse under a pressure increase of $15 \%$ in $7.5 \mathrm{~ms}$ is now considered, it leads to a density increase of around 7\%. The simulation results are shown in Figs. 11 and 12. Vaporization takes place in most of time during the collapse, except in a short duration of $2 \mathrm{~ms}$ just after the increase in the liquid pressure. In spite of this vaporization, the bubble III radius still decreases due to the compression of the liquid.

The temperature and pressure of the liquid at the bubble interface increase along the saturation line and approach the critical point at around $7.5 \mathrm{~ms}$ where the latent heat reduces to zero. The temperature and pressure of the vapor increase and the vapor enters the supercritical region before abruptly returning to the critical point. This trend can be explained on the basis of the vapor energy Eq. (18) as follows. At the beginning, although heat is evacuated from the vapor region through the inner thermal layer (term $I I<0$ ), the energy inside the bubble increases due to the pressure work (term $I>0$ ) and phase change (term $>0$ ). Note that both terms (I) and (II) increase (in their absolute value) with the increase in the vapor pressure and temperature whereas the term (III) decreases due to the convergence of fluid properties while approaching the critical point. As such, the energy inside the bubble starts to decrease when a sufficiently high temperature gradient is achieved in the inner thermal layer. Accordingly, the temperature and pressure of the vapor inside the bubble start to decrease steeply. Their abrupt change is seen to be merely connected to the rapid convergence of vapor and fluid properties, specifically the internal energy, near the critical point.

Finally the latent heat reduces to zero and there is no more phase change occurring at the bubble interface with all regions mixing together. Such a complex predicted mechanism, which certainly warrants an in-depth experimental validation conjugated with a completion of the numerical results analysis (eg. by supporting the thought with a $d R / d t$ analysis as carried out in [39] 

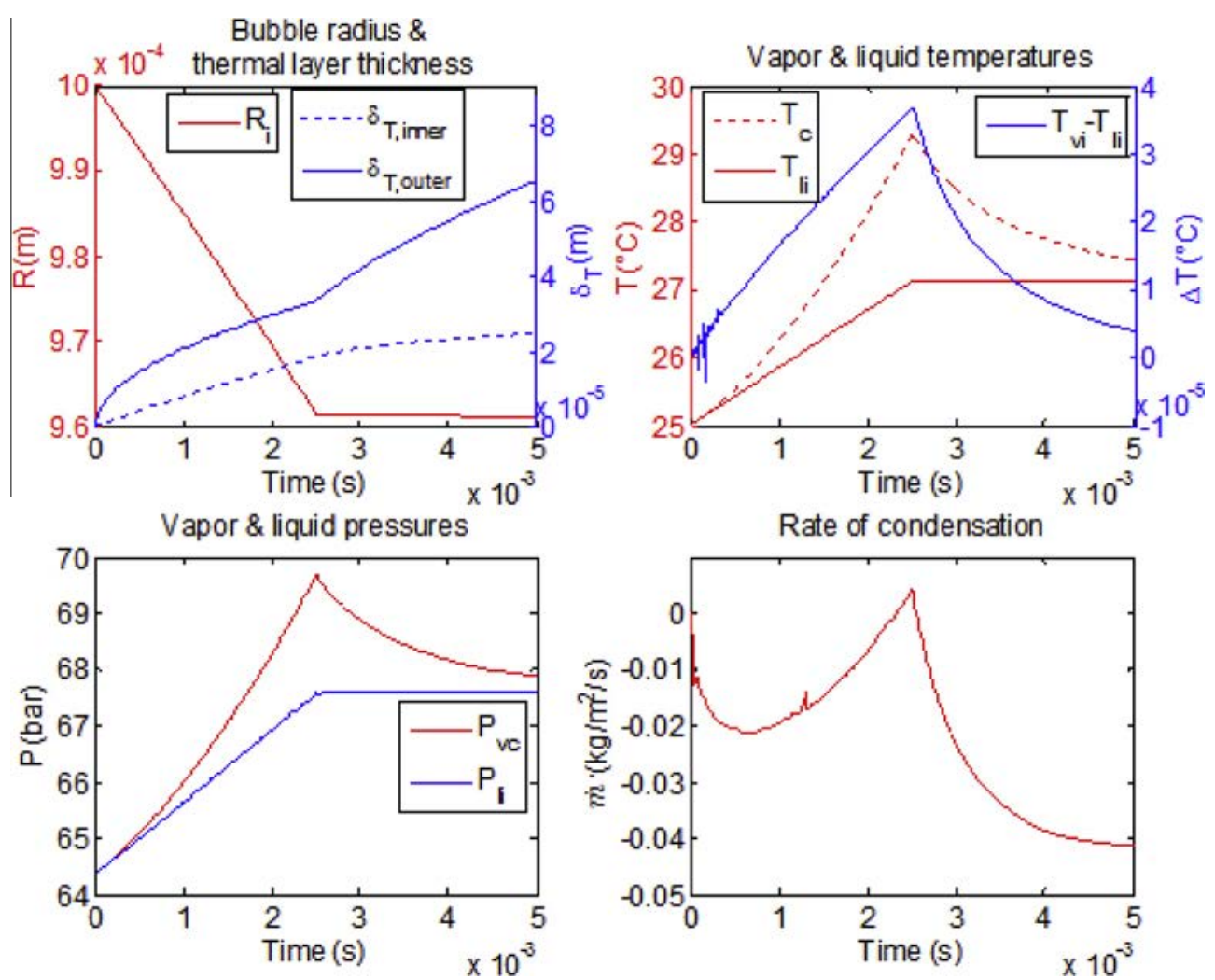

Fig. 9. Results of the $\mathrm{CO}_{2}$ bubble collapse under a $5 \%$ linear increase in the liquid pressure in $2.5 \mathrm{~ms}$ (calculation time $=5 \mathrm{~ms}$ ).
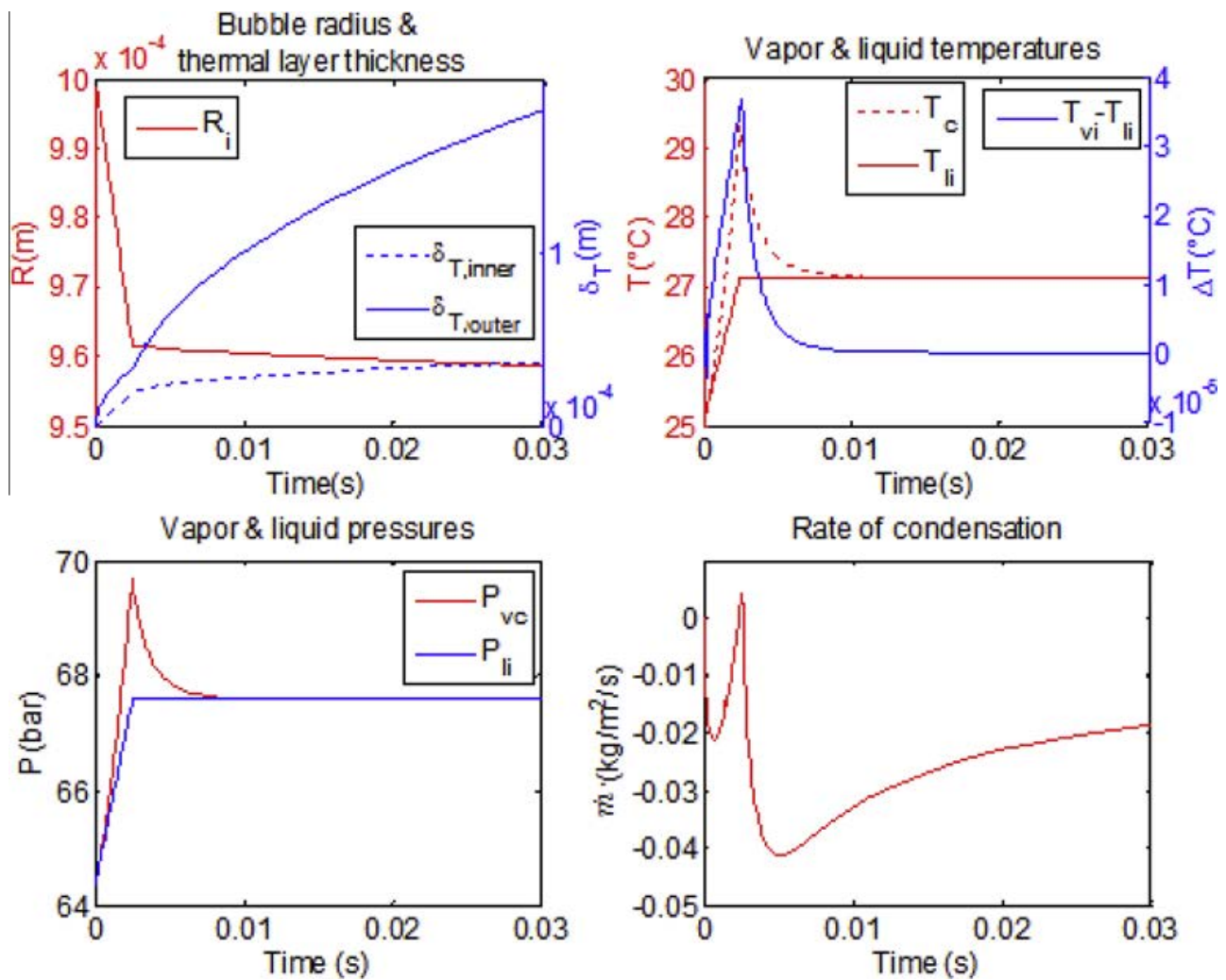

Fig. 10. Results of the $\mathrm{CO}_{2}$ bubble collapse under a $5 \%$ linear increase in the liquid pressure in $2.5 \mathrm{~ms}$ (calculation time = $30 \mathrm{~ms}$ ). 

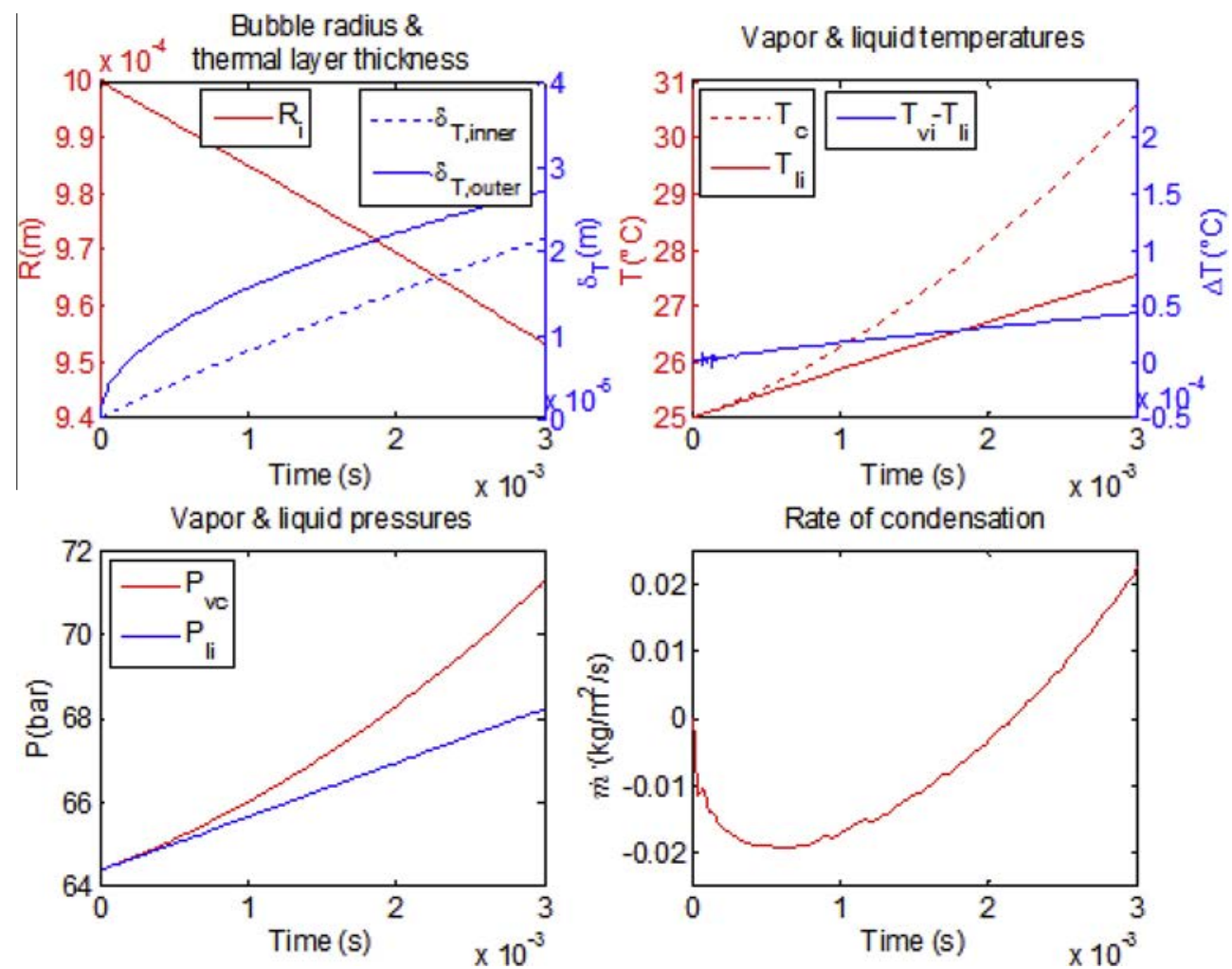

Fig. 11. Results of the $\mathrm{CO}_{2}$ bubble collapse under a $15 \%$ linear increase in the liquid pressure in $7.5 \mathrm{~ms}$ (calculation time $=3 \mathrm{~ms}$ ).

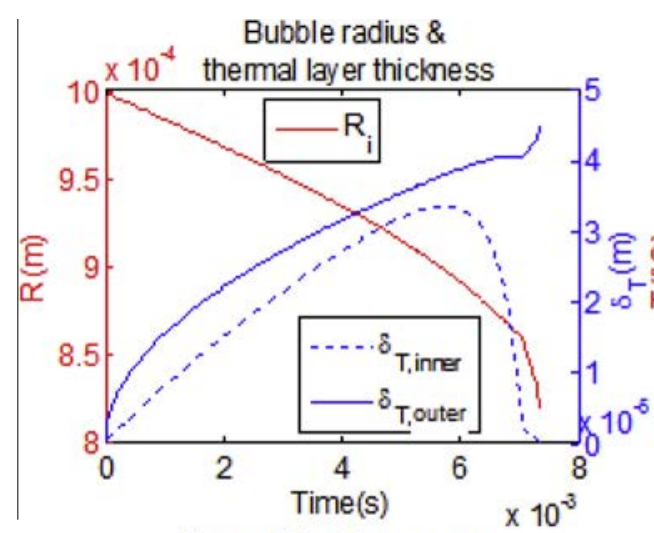

Vapor \& liquid pressures

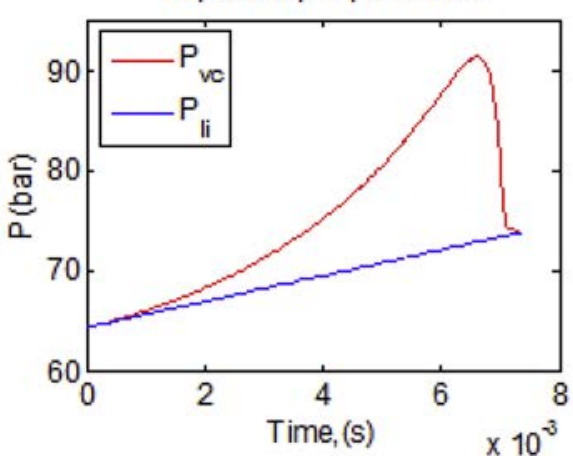

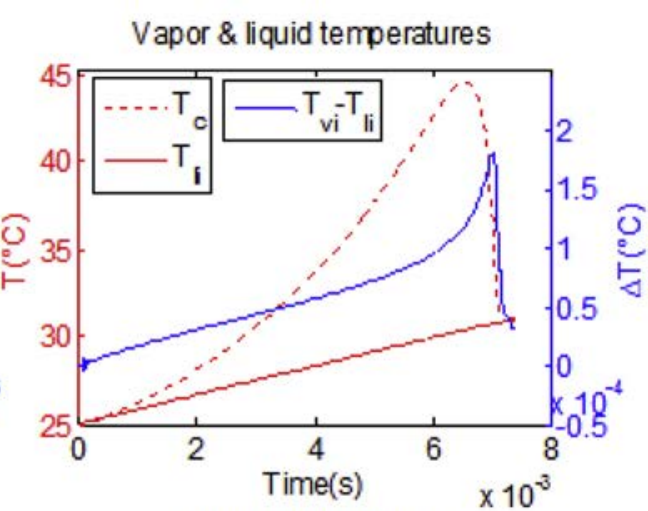

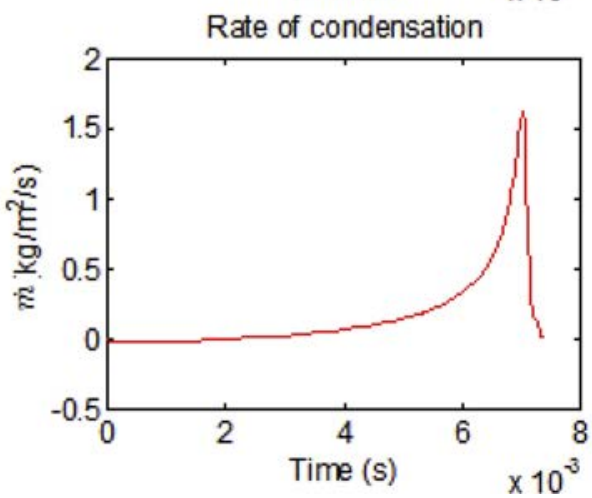

Fig. 12. Results of the $\mathrm{CO}_{2}$ bubble collapse under a $15 \%$ linear increase in the liquid pressure in $7.5 \mathrm{~ms}$. 
about acoustic cavitation)", suggests that the lack of cavitation damage could be understandable.

\section{Conclusions}

A numerical application of the characteristic parameters of the thermal effects has been performed at the beginning of this study. It has been suggested that thermal effects have significant implications on the bubble dynamics in $1 c-\mathrm{CO}_{2}$ (liquid $\mathrm{CO}_{2}$ near the critical point) by inhibiting early the motion of the bubble interface. The collapse of a $\mathrm{CO}_{2}$ bubble has therefore been predicted to feature a very slow contraction of the interface. A bubble dynamics model has then been proposed and successfully benchmarked with a previous study made on the collapse of a sodium bubble. Simulation results of the bubble collapse in $1 c-\mathrm{CO}_{2}$ have confirmed the very slow contraction of the bubble interface and demonstrated the absence of noticeable pressure rise. These also showed that the thermal layer inside the bubble has important effects on the bubble dynamics since it transfers a complementary heat flux to the interface. This heat flux has to be evacuated by the one from the interface to the liquid region, thereby altering the rate of condensation. With a sufficient increase in the liquid pressure, vaporization could occur during the bubble collapse, which was traditionally experienced only during the bubble growth. In addition, simulation results have suggested that if the increase in the liquid pressure is maintained, the vapor would enter the supercritical phase before approaching the critical point. The liquid region near the bubble interface would also reach this state by closely following the saturation line.

Note that due to various assumptions used in the model, these results should be directly validated in future experiments, since magnitudes of engaged pressure and temperature should afford such a possibility. Nonetheless, this investigation has provided qualitative and quantitative explanations of the non-detrimental effects associated with the bubble collapse in lc- $\mathrm{CO}_{2}$. These behaviors are seen to be in line with the experience gained through tests at Sandia National Laboratories. They could promisingly favor the operation of the compressor/pump in the liquid region at the lowest available temperature in view of improving the efficiency of the sc- $\mathrm{CO}_{2}$ cycle.

\section{References}

[1] G. Angelino, Real Gas Effects in Carbon Dioxide Cycles, 1969. ASME Paper No. 69-GT-103.

[2] G. Angelino, Carbon dioxide condensation cycles for power production, J. Eng Power 90 (1968) 287-295.

[3] C.E. Brennen, Cavitation and Bubble Dynamics, Oxford Engineering Science Series, Oxford University Press, New York, 1995.

[4] Y. Chen, Thermodynamic cycles using carbon dioxide as working fluid: $\mathrm{CO}_{2}$ transcritical power cycle study (Dissertation), KTH Royal Institute of Technology, 2011.

[5] V. Dostal, A supercritical carbon dioxide cycle for next generation nuclear reactors (Doctoral thesis), Massachusetts Institute of Technology, 2004.

[6] E.G. Feher, The supercritical thermodynamic power cycle, Energy Convers. 8 (1968) 85-90.

[7] L.W. Florschuetz, B.T. Chao, On the mechanics of vapor bubble collapse, J. Heat Transfer 87 (1965) 209-220, http://dx.doi.org/10.1115/1.3689075.

[8] J. Floyd, N. Alpy, D. Haubensack, G. Avakian, G. Rodriguez, On-design efficiency reference charts for the supercritical $\mathrm{CO}_{2}$ Brayton cycle coupled to an SFR, Proceedings of the 2011 International Congress on Advances in Nuclear Power Plants (ICAPP'11), Nice, France, 2011.

[9] J. Floyd, N. Alpy, A. Moisseytsev, D. Haubensack, G. Rodriguez, J. Sienicki, G. Avakian, A numerical investigation of the $\mathrm{SCO}_{2}$ recompression cycle off-design behaviour, coupled to a sodium-cooled fast reactor, for seasonal variation in the heat sink temperature, Nucl. Eng. Des. 260 (2013) 78-92.

[10] S. Fujikawa, T. Akamatsu, Effects of the non-equilibrium condensation of vapour on the pressure wave produced by the collapse of a bubble in a liquid, J. Fluid Mech. 97 (1980) 481-512, http://dx.doi.org/10.1017/ S0022112080002662.
[11] W. Garen, F. Hegedus, Y. Kai, S. Koch, B. Meyerer, W. Neu, U. Teubner, Shock wave emission during the collapse of cavitation bubbles, Shock Waves J. (2016), http://dx.doi.org/10.1007/s00193-015-0614-z.

[12] P. Hejzlar, V. Dostal, M.J. Driscoll, P. Dumaz, G. Poullennec, N. Alpy, Assessment of gas-cooled fast reactor with indirect supercritical $\mathrm{CO}_{2}$ cycle, Nucl. Eng. Technol. 38 (2006) 436-446.

[13] S. Ishiyama, Y. Muto, Y. Kato, S. Nishio, T. Hayashi, Y. Nomoto, Study of steam, helium and supercritical $\mathrm{CO}_{2}$ turbine power generations in prototype fusion power reactor, Prog. Nucl. Energy 50 (2008) 325-332.

[14] M. Kornfeld, L. Suvorov, On the destructive action of cavitation, J. Appl. Phys. 15 (2004) 495-506, http://dx.doi.org/10.1063/1.1707461.

[15] C. Lim, J.E. Kim, J.Y. Lee, H.Y. Kwak, Nonlinear behavior of micro bubbles under ultrasound due to heat transfer, J. Mech. Sci. Technol. 23 (2009) 2521-2528, http://dx.doi.org/10.1007/s12206-009-0702-z.

[16] F. Magaletti, L. Marino, C.M. Casciola, Shock formation in the collapse of a vapor nano-bubble in, Phys. Rev. Lett. 114 (6) (2014), http://dx.doi.org/ 10.1103/PhysRevLett.114.064501.

[17] R.S. Mohamed, G.A. Mansoori, The Use of Supercritical Fluid Extraction Technology in Food Processing, Food Technology Magazine, 2002.

[18] C.F. Naudé, A.T. Ellis, On the mechanism of cavitation damage by nonhemispherical cavities collapsing in contact with a solid boundary, J. Basic Eng. 83 (1961) 648-656, http://dx.doi.org/10.1115/1.3662286.

[19] J.S. Noall, J.J. Pasch, Achievable efficiency and stability of supercritical $\mathrm{CO}_{2}$ compression systems, Supercritical $\mathrm{CO}_{2}$ Power Cycle Symposium, Pittsburgh, Pennsylvania, 2014.

[20] H.S. Pham, N. Alpy, J.H. Ferrasse, O. Boutin, J. Quenaut, M. Tothill, D. Haubensack, M. Saez, Mapping of the thermodynamic performance of the supercritical $\mathrm{CO}_{2}$ cycle and optimisation for a small modular reactor and a sodium-cooled fast reactor, Energy 87 (2015) 412-424, http://dx.doi.org/ 10.1016/j.energy.2015.05.022.

[21] M.S. Plesset, The dynamics of cavitation bubbles, J. Appl. Phys. 16 (1949) $277-$ 282.

[22] M.S. Plesset, R.B. Chapman, Collapse of an initially spherical vapour cavity in the neighbourhood of a solid boundary, J. Fluid Mech. 47 (1971) 283, http://dx. doi.org/10.1017/S0022112071001058.

[23] Lord. Rayleigh, On the pressure developed in a liquid during the collapse of a spherical cavity, Philos. Mag. Ser. 6 (34) (1917) 94-98, http://dx.doi.org/ 10.1080/14786440808635681.

[24] D. Sanchez, R. Chacartegui, F. Jimenez-Espadafor, T. Sanchez, A new concept for high temperature fuel cell hybrid systems using supercritical carbon dioxide, J. Fuel Cell Sci. Technol. 6 (2009).

[25] L.E. Scriven, On the dynamics of phase growth, Chem. Eng. Sci. 10 (1959) 1-13, http://dx.doi.org/10.1016/0009-2509(59)80019-1.

[26] J.J. Sienicki, SSTAR Lead-cooled, Small Modular Fast Reactor with Nitride Fuel, 2005.

[27] R. Span, W. Wagner, A new equation of state for carbon dioxide covering the fluid region from the triple-point temperature to $1100 \mathrm{~K}$ at pressures up to 800 MPa, J. Phys. Chem. Ref. Data 25 (1996) 1509.

[28] A.J. Stepanoff, Cavitation properties of liquids, J. Eng. Power 86 (1964) 195199, http://dx.doi.org/10.1115/1.3677576.

[29] B. Sulzer, Sulzer Patent Verfahren zur Erzeugung von Arbeit aus Warme, 1948.

[30] T. Theofanous, L. Biasi, H.S. Isbin, H. Fauske, A theoretical study on bubble growth in constant and time-dependent pressure fields, Chem. Eng. Sci. 24 (1969) 885-897, http://dx.doi.org/10.1016/0009-2509(69)85008-6.

[31] T.G. Theofanous, L. Biasi, H.S. Isbin, H.K. Fauske, Nonequilibrium Bubble Collapse: A Theoretical Study, 1970.

[32] C.-C. Tseng, W. Shyy, Modeling for isothermal and cryogenic cavitation, Int. J. Heat Mass Transfer 53 (2010) 513-525, http://dx.doi.org/10.1016/j. ijheatmasstransfer.2009.09.005.

[33] C.S. Turchi, Z. Ma, T.W. Neises, M.J. Wagner, Thermodynamic study of advanced supercritical carbon dioxide power cycles for concentrating solar power systems, J. Sol. Energy Eng. 135 (2013) 041007.

[34] M. Vanderhaegen, Modeling of the acoustic boiling noise of sodium during an assembly blockage in sodium-cooled reactors (Ph.D. thesis), Université Paris Dirderot, Paris, France, 2013.

[35] M.M. van Iersel, J. Cornel, N.E. Benes, J.T.F. Keurentjes, Inhibition of nonlinear acoustic cavitation dynamics in liquid $\mathrm{CO}_{2}$, J. Chem. Phys. 126 (2007) 064508, http://dx.doi.org/10.1063/1.2434962.

[36] P.M. Winkler, A. Vrtala, R. Rudolf, P.E. Wagner, I. Riipinen, T. Vesala, K.E.J. Lehtinen, Y. Viisanen, M. Kulmala, Condensation of water vapor: experimental determination of mass and thermal accommodation coefficients, J. Geophys. Res. 111 (2006) D19202, http://dx.doi.org/10.1029/2006JD007194.

[37] S.A. Wright, R.F. Radel, M.E. Vernon, P.S. Pickard, G.E. Rochau, Operation and Analysis of a Supercritical $\mathrm{CO}_{2}$ Brayton Cycle, 2010.

[38] S.-H. Yang, S.-Y. Jaw, K.-C. Yeh, Single cavitation bubble generation and observation of the bubble collapse flow induced by a pressure wave, Exp. Fluids 47 (2009) 343-355, http://dx.doi.org/10.1007/s00348-009-0670-1.

[39] K. Yasui, A. Towata, T. Tuziuti, T. Kozukaa, K. Kato, K. Yasui, Effect of static pressure on acoustic energy radiated by cavitation bubbles in viscous liquids under ultrasound, J. Acoust. Soc. Am. 130 (2011) 3233-3242, http://dx.doi.org/ $10.1121 / 1.3626130$.

[40] H.J. Yoon, Y. Ahn, J.I. Lee, Y. Addad, Potential advantages of coupling supercritical $\mathrm{CO}_{2}$ Brayton cycle to water-cooled small and medium size reactor, Nucl. Eng. Des. 245 (2012) 223-232. 